\section{The Perception and Usefulness of Problem Based Learning Among Medical Students}

Presented at 1st International Online BioMedical Conference

ORIGINAL

\section{Abstract}

Background: Problem Based Learning (PBL) has been increasing adopted in medical school worldwide. Problem based learning is an instructional strategy in which learner-centred method is utilised and "problems" are used as the focus of learning in small groups. Problembased learning grounded in cognitive theory and with its origins in medical education, is a useful approach for teaching students how to think critically and solve problems they will encounter.

Objectives: To determine the student's perception and usefulness of problem based learning among the clinical specialties of medical departments of Melaka Manipal Medical College.

Methodology: College based cross sectional study was conducted at Melaka Manipal Medical College, Melaka, Malaysia from August to October 2012. Self-administered questionnaires were distributed to final year medical students who had undergone PBL classes in all discipline. Data were analyzed by using SPSS 16 software. To assess perception, five points Likert scale was used for scoring.

Results: There were 220 students participated in this study and majority of the respondents were Malay 84 (38.2\%) with mean age of 23 years (SD: 0.88). Most of the students (78.3\%) perceived that facilitator motivated them to study during the session, (76.9\%) perceived that PBL classes were well plan and structure and (75\%) of them perceived that PBL classes helped them to identify the weakness in learning topics and to develop communication skill. Regarding usefulness of PBL classes more than $90 \%$ of students stated that PBL classes helped them to develop team collaboration, self-directed learning, and problem solving skill.
Kye Mon Min Swe', Amit Bhardwaj ${ }^{1}$, Kavitha Nagandla², Adinegara Bin Lutfi Abas, Nimal Kumar Sinha ${ }^{1}$

1 Melaka Manipal Medical College, Melaka, Malaysia.

2 International Medical University, Malaysia.

\section{Contact information:}

Kye Mon Min Swe.

”khmoneminswe@gmail.com 
Study Limitations: This is the cross-sessional study regarding the student's perception on usefulness of problem based study. It will be better if we can perform intervention study regarding usefulness of the PBL classes.

Conclusions: There is strong evidence that students have positive perception on PBL classes and helped them to develop scientific basis of deep and structured learning. However, there is a need to continually evaluate teaching strategies employed within medical schools to ensure effective learning.

\section{Keywords \\ PBL; Medical students; \\ Perception; Malaysia.}

\section{Introduction}

Problem Based Learning (PBL) has been increasing adopted in medical school worldwide. Problem based learning is an instructional strategy in which learner-centred method is utilised and "problems" are used as the focus of learning in small groups. Problem-based learning grounded in cognitive theory and with its origins in medical education, is a useful approach for teaching students how to think critically and solve problems they will encounter. [1]

PBL has disadvantages as well as advantages. However, such method is found to be more effective than learning based on established disciplines in the traditional curriculum. [2] Traditional undergraduate medical school curricula are often divided into pre-clinical and clinical years, and are dominated by a teacher-centred, reductionist approach, with a didactic, fragmentary manner usually in large lecture theatres by teachers with expertise in the areas of their research interests. [3]

Problem-based learning (PBL), however, provides opportunities for authentic, integrated problems to drive the learning of undergraduate students and to reduce the burden of factual information. Underpinned by constructivist, experiential, adult learning principles. [4] PBL is increasingly considered to be among the best educational practices that medical schools internationally are adopting as they revitalize their curricula and shift to a learner-centred focus.

Over the last 20 years, there has been increasing interest in problem-based learning (PBL) in undergraduate medical education. PBL was pioneered by the McMaster Medical School in Canada in 1969 and soon, thereafter many medical and health institutes across the world adopted this innovative approach. PBL is an instructional strategy in which learner-centred method is adopted and students learn by working on real life problems and activities, where teacher acts as a facilitator. [5] PBL embraces a pedagogic theory intended for enhancing self-motivation, active, life-long learning, critical thinking, professional behaviours, effective communication and collaborative team-work approaches of students. [6] However, for PBL to be effective, construction of well-designed cases/problems that drive meaningful learning is crucial as these are the starting point for students' learning activities that largely impact on the quality of student learning. [7]

Problem-based learning occurs in the context of a community of learners who share the same objective: solving the problem. Ideally, the group should consist of 5 to 7 members but can be modified to accommodate up to 14 members. Unlike the lecture 
format, the PBL process addresses group dynamics, including the relationships and contributions of each group member. Leadership, cooperation, communication, resource utilization, collaborative team building, and decision making skills are crucial to group success and are developed through the PBL learning process. The active-learning process of the $\mathrm{PBL}$ environment allows the learner to engage the real world problem with enthusiasm, initiative, and inherent motivation because the knowledge acquired is integrated, flexible, and immediately useful. The content to be learned is immediately important and relevant to the learner's life and career. The PBL process likely facilitates the development of the relationship among learning, cognitive competence, and motivation. [8]

In our college, PBL classes were conducted under guideline of each department. We would like to determine the student's perception and usefulness of problem based learning and their opinion on how to improve their PBL classes better. From this research result will give perception and usefulness of PBL classes on the students and that can apply on the improvement of PBL classes among disciplines.

\section{Objectives}

To determine the student's perception and usefulness of problem based learning among the clinical specialties of medical departments of Melaka Manipal Medical College.

\section{Material and Methods}

College based cross sectional study design was conducted at Melaka Manipal Medical College, Melaka, Malaysia from August to October 2012.

Data was collected in the form of pre-tested self-administered questionnaires. Each questionnaire consisted of FOUR sections, Section (A) Socio-demographic character, Section (B) - Usefulness of PBL classes, Section (C) - Perception of PBL classes and Section (D) Student's opinion to improve PBL classes. In order to standardize the questionnaires, a pilot study was conducted among the third year medical students; content validity was examined.

The pre-tested structured closed ended questionnaires were distributed to all the final year students during their PBL classes. The purpose of the study was explained and informed written consent was obtained. All the collected data were tabulated and analyzed by using the statistical package for social science, SPSS, version 16.0. The data were screened for accuracy and incomplete data were excluded from analysis. To assess perception, five points Likert scale was used for scoring, 5. Strongly agree, 4. Agree 3. Not Sure 2. Disagree and 1. Strongly Disagree. Operational definition for problem based learning is the learning that results from the process of working towards the understanding or resolution of the problem. Perception was defined as way of understanding upon peer assisted learning by the students. The study was approved by research committee Melaka Manipal Medical College on May 2012.

\section{Results}

There were total 254 students in the academic year belonging to the final year and among them 220 respondents participated in this study which gave a response rate of $87.7 \%$. It was found that majority of the respondents were Malay 84 (38.2\%), followed by Chinese 65 (29.5\%) and Indian 60 (27.3\%). The mean age of respondents was 23 years (SD- 0.88 ). The sex distribution revealed that the majority of the respondents 147 (66.8\%) were female.

\section{Perception of students on their PBL session classes}

Total 13 perception statements with three negative and ten positive statements were used to assess the students' perception on their PBL classes. The 
response (\%) of perception of students on their PBL session was shown in table 1.

The students perceived positively on the PBL classes were well plan and structure (76.9\%), PBL classes' link to the lecture classes (52.7\%), PBL classes covered all areas in key topic (69.5\%) and PBL classes help to identify the weakness in learning topics (75.0\%). In this study $70.0 \%$ of students perceived positively on the statements" PBL classes motivate self-study", $68.6 \%$ of students strongly agree and agree on the statement "Facilitators were devoted and gave sufficient time to each students", 78.3\% of the students gave positive response to the statement "Facilitators were encouraged to motivate me to study about the topic" and $56.8 \%$ of them stated that PBL classes made them increase Level of understanding.

\section{Usefulness of PBL session}

Regarding usefulness of PBL classes above $90 \%$ of students stated that PBL classes developed team collaboration, self-directed learning, and problem solving skill. Figure 1

\section{The student's opinion to improve PBL session}

We have assessed the student's opinion to improve PBL session by statements as well as open ended questions. Regarding the statement "I wish PBL classes to be more interactive" $71.4 \%$ of the student strongly agree and agree on that statement and $71.6 \%$ of the students stated that "Some PBL classes need to be conduct in small group discussion".

The students gave opinion to things to improve in PBL session and $31.8 \%$ of them stated that PBL classes need more interaction, $18.2 \%$ prefer less students teacher ratio and $46.4 \%$ of them prefer to discuss real case scenario in PBL session. Figure 2

\section{Discussion}

There were total 220 respondents participated in this study. It was found that majority of the respondents were Malay 220 (38.2\%). The mean age of respondents was 23 years (SD: 0.88). The sex distribution revealed that the majority of the respondents were 147 (66.8\%) female.

Table 1. Responses (\%) of perception of students on their PBL session classes.

\begin{tabular}{|l|c|c|c|c|c|}
\hline \multicolumn{1}{|c|}{ Statement } & SA & A & U & DA & SDA \\
\hline PBL classes were well planned and structured & 11.4 & 65.5 & 17.3 & 3.6 & 2.2 \\
\hline PBL classes were not link to lecture class & 2.7 & 23.6 & 20.9 & 44.5 & 8.2 \\
\hline PBL classes covered all areas in key topics & 6.8 & 62.7 & 24.1 & 6.4 & 0 \\
\hline PBL classes helped to identify the weakness in learning topics & 9.5 & 65.5 & 21.8 & 3.2 & 0 \\
\hline The concepts of topics became clear after PBL classes & 12.3 & 61.4 & 23.2 & 3.2 & 0 \\
\hline PBL classes motivated self-study & 18.6 & 51.4 & 25.5 & 3.2 & 1.4 \\
\hline Facilitators were devoted and gave sufficient time to each students & 14.1 & 54.5 & 26.4 & 4.5 & 0.5 \\
\hline Facilitators were encouraged to motivate me to study about the topic & 13.8 & 64.5 & 18.2 & 3.2 & 0.5 \\
\hline Level of understanding not much increased after PBL classes & 1.4 & 18.6 & 23.2 & 50.9 & 5.9 \\
\hline PBL classes helped to develop communication skill & 11.8 & 63.2 & 17.3 & 7.7 & 0 \\
\hline PBL classes did not help much for exam & 0.9 & 13.2 & 28.2 & 45.5 & 12.3 \\
\hline I wish PBL classes to be more interactive & 10.9 & 60.5 & 20.9 & 7.7 & 0 \\
\hline Some PBL classes need to be conduct in small group discussion & 20.5 & 51.4 & 21.8 & 5.5 & 0.9 \\
\hline
\end{tabular}


Figure 1: Usefulness of PBL classes.

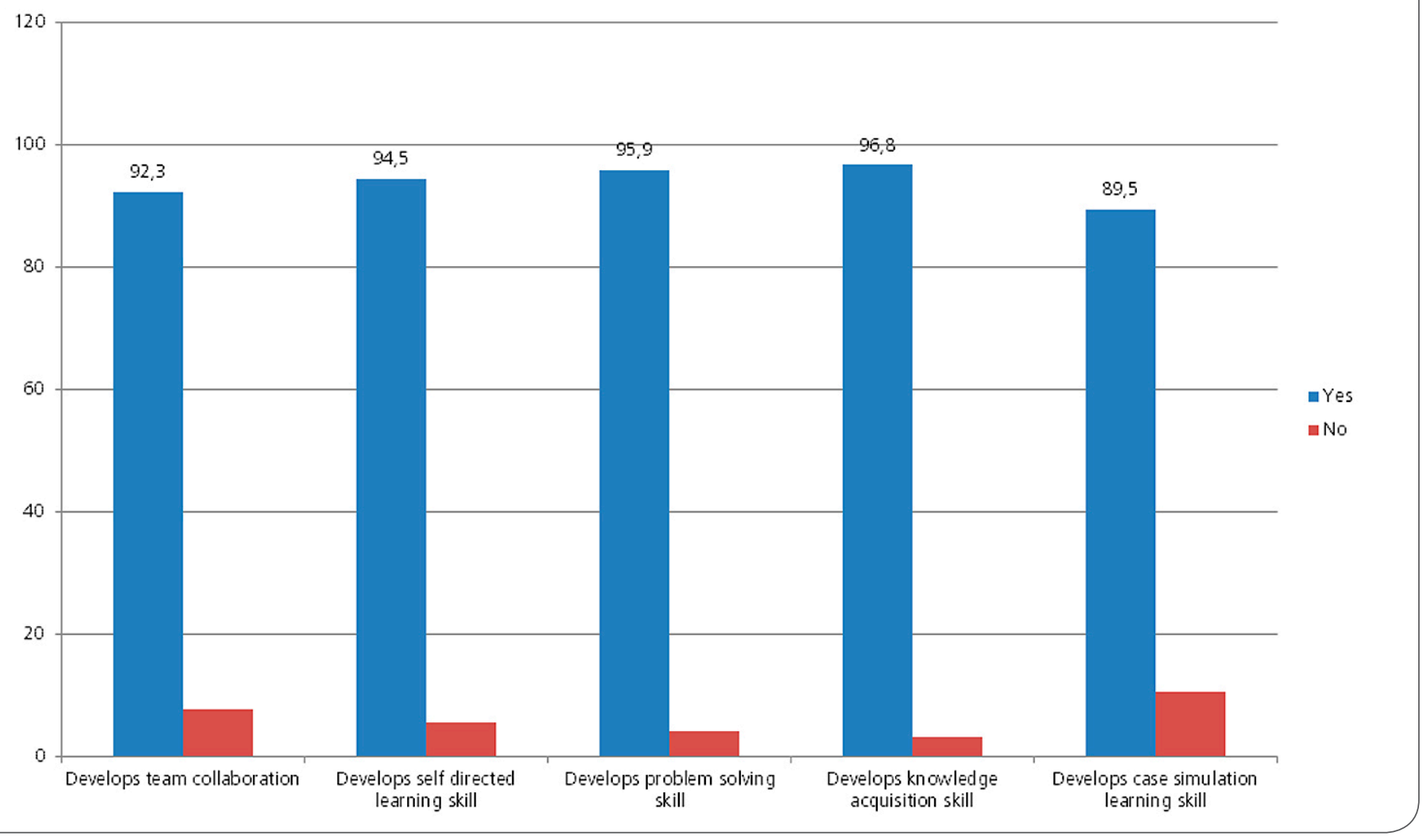

Figure 2: Things need to be improved in PBL classes.

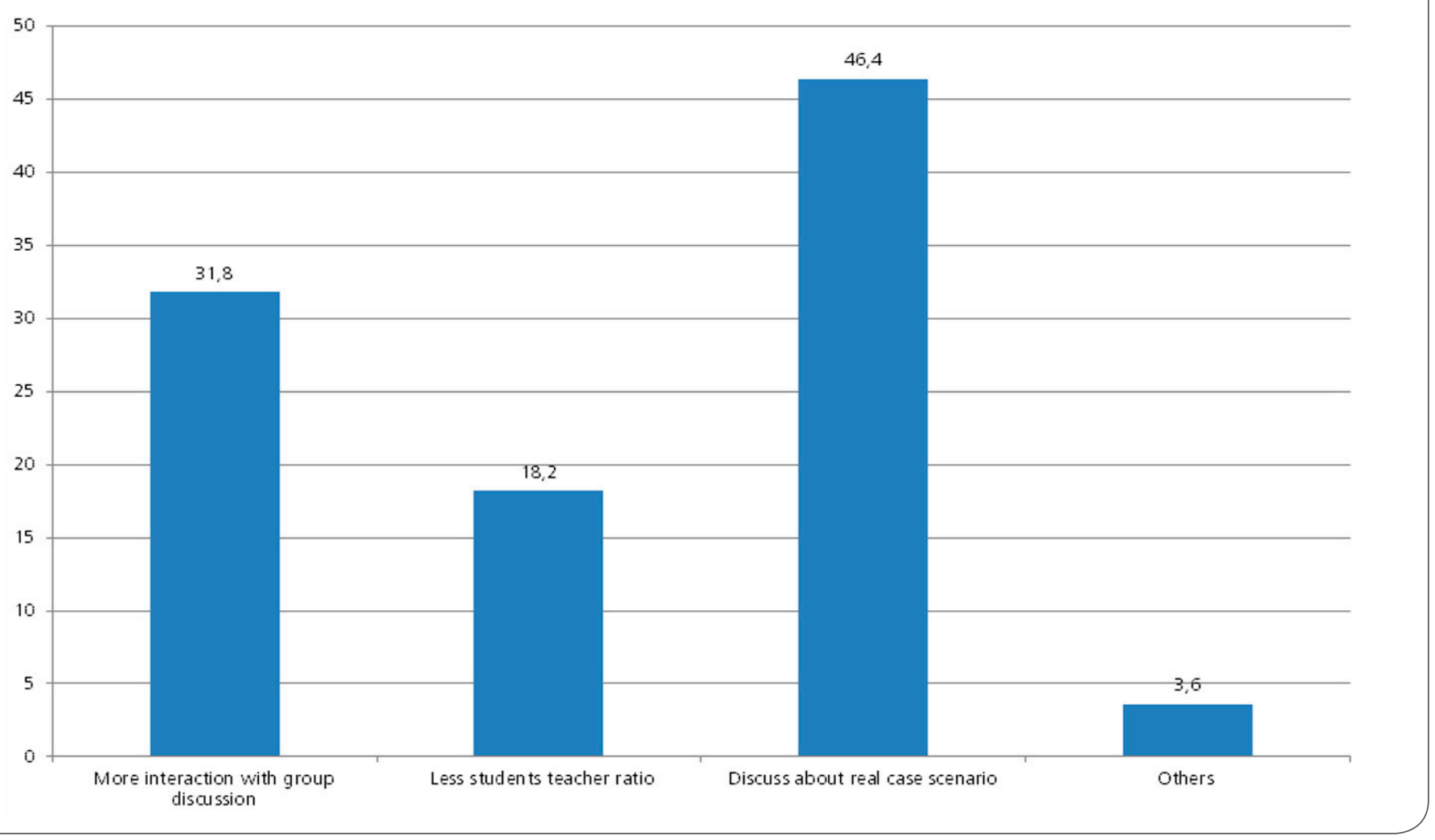




\section{Perception of PBL classes}

Total 13 perception statements were used to assess the perception of students on PBL classes. The students perceived positively on the PBL classes were well plan and structure (76.9\%), PBL class's link to the lecture classes (52.7\%), PBL classes covered all areas in key topic $(69.5 \%)$ and PBL classes help to identify the weakness in learning topics (75.0\%). In a study Chang et al 2004, most students preferred PBL in the following 6 aspects: learning about anesthesia, understanding other medical knowledge, being interested in and motivated to learn, training for future work, training of personal abilities, and being confident and satisfied with the teaching method $(p<0.05)$. [9]

In this study $70.0 \%$ of students perceived positively on the statements" PBL classes motivate self-study" In a study Kong et al 2009, the students believed that introducing PBL into ophthalmology could improve educational quality and effectiveness. Digital PBL cases stimulate interest and motivate students to further improve diagnosis and problem-handling skills. [18] In a study by HoffMAN et al 2006, the PBL curricular changes implemented with the graduating class resulted in higher performances on USMLEs. These changes better prepare graduates with knowledge and skills needed to practice within a complex health care system. Outcomes reported in a study support the investment of financial and human resources in the PBL curriculum. [19]

In this study $68.6 \%$ of students strongly agree and agree on the statement "Facilitators were devoted and gave sufficient time to each students" and $78.3 \%$ of the students gave positive response to the statement "Facilitators were encouraged to motivate me to study about the topic" and 56.8\% of them stated that PBL classes made them increase Level of understanding

In a study Bermen A et al 2006 the students perceived that PBL helped them with in-depth understanding of certain topics and link their basic science knowledge to clinical classes. They felt that guidance from subject specialists and wellprepared facilitators of the sessions were beneficial. [12] In a study Cheng et al 2004 the students prefer to modified the assessment tools and content of PBL to implement of PBL for teaching anesthesia. [9]

In a study Bhattacharya $\mathrm{N}$, the respondent found out that both students and teachers found PBL rewarding. Implementation of $\mathrm{PBL}$ is feasible even in a traditional set-up despite limited resources, rigid time schedules and little interaction among various disciplines. [13] In a study Bermen A et al 2006, PBL classes provided guidelines for searching for resource materials and briefing the students and facilitators about the philosophy and principles of PBL may make the PBL sessions more beneficial. [12] In a study by Burguns et al, it was evaluated PBL versus academic courses and the results showed significantly higher scores for PBL (McNemar test $\mathrm{p}$ $<0.0001)$. [12]

We have assessed the student's opinion to improve PBL session by statements as well as open ended questions. Regarding the statement "I wish PBL classes to be more interactive'" $71.4 \%$ of the student strongly agree and agree on that statement and $71.6 \%$ of the students stated that "Some PBL classes need to be conduct in small group discussion".

The students gave opinion to things to improve in PBL session and $31.8 \%$ of them stated that PBL classes need more interaction, $18.2 \%$ prefer less students teacher ratio and $46.4 \%$ of them prefer to discuss real case scenario in PBL session. In a study BERMEN et al 2006, most students reported their participation in discussion during PBL sessions but the level of participation varied. Some of them worked hard to prepare themselves for discussion while others were relatively passive. [12]

There are some studies that the student preferred PBL classes than traditional tutorial classes. According to Koh, PBL undergraduate students are used 
to working in a poorly structured education environment and, therefore, are encouraged to work independently. Furthermore, they often work in small groups, which encourage them to develop good communication among themselves but the study observed that PBL students feel less confident when compared to traditional learning method students. PBL students may feel insecure exactly because they are required to work on an independent basis instead of playing a secondary role in the learning process. [11] The study by Millan stated that traditional learning method students consider themselves to be better prepared for internship activities than PBL students, according to the following three comparative means: by analyzing the answers to each question, by grouping these answers into dimensions, and by calculating the means of answers to the whole questionnaire. [17]

\section{Conclusion and Recommendation}

The study result revealed that there is strong evidence that students have positive perception on PBL classes and helped them to develop scientific basis of deep and structured learning. However, there is a need to continually evaluate teaching strategies employed within medical schools to ensure effective learning.

\section{Conflict of interest}

It was declared that there is no conflict of interest that might bias the outcomes of the paper.

\section{References}

1. Barrows HS. Problem-Based Learning Applied to Medical Education. Springfield, IL: Southern Illinois University Medical School; 2000: 1-11

2. Majumder MAA. Pros and cons of problem-based learning. Bangladesh Medical Journal 2004, 33, 67-69

3. Steinert Y. Student perceptions of effective small group teaching. Med Educ 2004; 38: 286-93

4. Hmelo-Silver CE. Problem-based learning: what and how students learn. Educ Psychol Rev 2004; 16(3): 235-66

5. Barrows H.S, Tamblyn R. Problem-based Learning: An Approach to Medical Education. New York: Springer 1980.

6. Dolmans DH, Snell-Balendong $H$, Wolfhagen IHAP, van der Vleuten CP. Seven principles of effective case design for a problem-based curriculum. Med Teacher 1997; 19(3): 185-9

7. Dolmans DH, De Grave W, Wolfhagen IH, Van der Vleuten CP. Problem-based learning: Future challenges for educational practice and research. Med Educ 2005; 39: 732-41

8. Barrows, H.S. (1996) What Your Tutor May Never Tell You: A Guide for Medical Students in Problem-Based Learning. Southern Illinois University School of Medicine; Springfield, IL.

9. Chang $\mathrm{CH}$, Yang CY, See LC. High Satisfaction with ProblemBased Learning for Anesthesia. Chang Gung Med J, 27(9), 2004.

10. Luh Shi-Ping, Yu Min-Ning, Lin Yen-Ru, Chou Ming-Jen.A Study on the Personal Traits and Knowledge Base of Taiwanese Medical Students Following Problem-based Learning Instructions. Annals Academy of Medicine, 36(9), 2007.

11. Koh, G.C., Khoo, H.E., Wong, M.L., Koh, D. The effect of problem-based learning during medical school on physician competency: a systematic review. Can Med Assoc J, 2008; 178 : 34-41.

12. Barman Arunodaya, Jaafar Rogayah, Ismail Noorliza Mastura. problem-based learning as perceived by dental students in universiti sains Malaysia. Malaysian Journal Of Medical Science, 2006; 13(1).

13. Bhattacharya, N., Shankar, N., Khaliq, F., Rajesh, C.S., Tandon, O.P. Introducing problem-based learning in physiology in the conventional Indian medical curriculum. Natl Med J India, 2005; 18 (2): 92-5.

14. Sulaiman N, Hamdy $H$. Problem-based learning: Where are we now? Guide supplement 36.3 - Practical Application. Med Teach. 2012. 
15. Dolder CR, Olin JL, Alston GL. Prospective measurement of a problem-based learning course sequence. Am J Pharm Educ. 2012 Nov 12; 76(9): 179.

16. Addae JI, Wilson JI, Carrington C. Students' perception of a modified form of PBL using concept mapping. Med Teach. 2012; 34(11): e756-62.

17. Millan LP, Semer B, Rodrigues JM, Gianini RJ. Traditional learning and problem-based learning: self-perception of preparedness for internship. Rev Assoc Med Bras. 2012 Oct; 58(5): 594-9.

18. Kong, J., Li, X., Wang, Y., Sun, W., Zhang, J. (2009) Effect of digital problem-based learning cases on student learning outcomes in ophthalmology courses. Arch Ophthalmol, 127(9): 1211-4.

19. Hoffman K, Hosokawa M, Blake R Jr, Headrick L, Johnson G. Problem-based learning outcomes: ten years of experience at the University of Missouri-Columbia School of Medicine Acad Med. 2006 Jul; 81(7): 617-25

\section{Comment on this article:}

\section{(f) B in $8+8$}
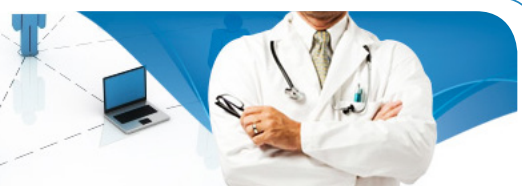

\section{http://medicalia.org/}

Where Doctors exchange clinical experiences, review their cases and share clinical knowledge. You can also access lots of medical publications for free. Join Now!

\section{Publish with iMedPub}

\section{http://www.imed.pub}

International Archives of Medicine is an open access journal publishing articles encompassing all aspects of medical science and clinical practice. IAM is considered a megajournal with independent sections on all areas of medicine. IAM is a really international journal with authors and board members from all around the world. The journal is widely indexed and classified Q1 in category Medicine. 